\title{
Wichtig sind Schutz vor Grippe, Pneumokokken und Keuchhusten
}

\author{
Influenza-Viren, Pneumokokken und Bordetella pertussis. Diese Erreger können zu schweren \\ pulmonalen Komplikationen führen. Das ist umso tragischer, als sie durch eine Impfung ver- \\ hindert werden könnten.
}

\begin{abstract}
— „Die Grippe-Epidemie in der letzten Saison war geprägt von besonderen Herausforderungen und Schwierigkeiten", so Prof. Tobias Welte, Hannover. Mit dem H3N2-Virus, einer Variante des Hongkong-Virus, habe sich ein besonders pathogener Virusstamm ausgebreitet, und mit einer Effektivität von 30\% sei der Impfstoff nicht besonders wirksam gewesen. Dazu kamen Lieferschwierigkeiten beim Impfstoff. Die Impfrate ist weiterhin niedrig. Gemeldet wurden bisher über 100.000 Infektionen mit mehr als 500 Todesfällen. Auch war die Krankenhausbehandlungsrate höher als 2015 - ein zuverlässiger Indikator für die Schwere der Erkrankung.
\end{abstract}

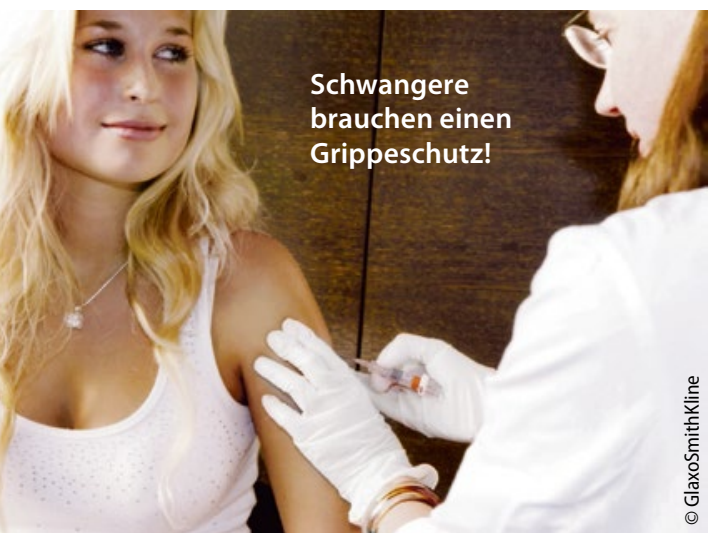

Prävention des Herzinfarktes

„Der neue Standard bei der Grippe-Impfung wird ein quadrivalenter Impfstoff sein, denn er ist deutlich effektiver als der trivalente", so Welte. Es gebe keine Zweifel daran, dass die Grippeimpfung wirksam ist. „Weniger Tote, weniger Komplikationen, weniger Krankenhaus- behandlungen, weniger Herzinfarkte und weniger kardiale Dekompensationen", so Welte. Man könnte auch sagen, die Grippe-Impfung ist die effektivste Prävention des Herzinfarktes.

\section{Wer soll geimpft werden?}

Für Kinder gibt es in Deutschland keine generelle Impfempfehlung. Geimpft werden sollen aber alle Über-65-Jährigen, außerdem Patienten mit Immunsuppression oder einer chronischen Herz-, Nieren-, Leber-, Lungen-, Blut- oder metabolischen Erkrankung. „Besonders wichtig ist die Impfung von Schwangeren, da bei ihnen die Grippe sehr schwer verlaufen kann", so Welte. Die Impfung schütze nicht nur die Mutter, sondern auch das Neugeborene. Die Grippeimpfung sei in jedem Trimenon möglich.

\section{Unerfreuliche Situation bei Pneumokokkenimpfung}

„Bei der Pneumokokkenimpfung, genauer gesagt bei der Wahl des Impfstoffs, gibt es widersprüchliche Empfehlungen“, so Welte. Das sei unerfreulich und führe zu Verunsicherungen. So empfiehlt die sächsische Impfkommission und die S3-Leitlinie der Deutschen Gesellschaft für Pneumologie nach den Ergebnissen der CAPITA-Studie für Personen über 60 Jahre den konjugierten 13-valenten Impfstoff (PCV 13), die STIKO dagegen rät auf der Basis einer Metaanalyse zur Impfung mit dem Polysaccharid-Impfstoff PSV 23 und einer Auffrischimpfung mit PSV 23 nach 6 Jahren. In der CAPITA-Studie konnte mit PCV 13 die Häufigkeit einer Pneumokokkenpneumonie um 45,6\% und die Bakteriämie-Rate sogar um 75\% gesenkt werden. Nach der S3-Leitlinie sollte bei Risikopatienten mit chronischer Herz-, Leber-, Lungen- oder Nierenerkrankung bzw. bei einer Immunsuppression eine Sequenzimpfung durchgeführt werden, d.h. 6 bis 12 Monate nach der PCV-13-Impfung sollte sich eine Impfung mit PSV 23 anschließen. Auch die STIKO empfiehlt für diese Patienten eine Sequenzimpfung, schließt jedoch chronisch Herz- und/oder Lungenkranke und Diabetiker nicht in die Risikopopulation ein.

\section{Neue Keuchhusten-Welle}

Früher wurde mit zellulären Impfstoffen gegen Keuchhusten geimpft. „Dieser Impfstoff war sehr immunogen, führte aber nicht selten zu schweren Nebenwirkungen, weshalb man auf einen besser verträglichen azellulären Impfstoff wechselte", so Welte. Dieser ist jedoch weniger immunogen, die Wirkung hält nur 10 bis 15 Jahre an. Also hätte man allen nach dieser Zeit eine Auffrisch-Impfung geben müssen. „Dies ist unterblieben, sodass wir heute immer mehr Keuchhustenfälle bei Erwachsenen mit zum Teil schweren Verläufen sehen", so Welte. Erlischt der Impfschutz, können sich Menschen sogar nach einer überwundenen Infektion neu anstecken. Um die zunehmende Verlagerung der Erkrankung ins Erwachsenenalter aufzuhalten, solle man bei der nächsten Tetanus-Impfung auch gegen Pertussis impfen, empfahl Welte.

\section{Dr. Peter Stiefelhagen}

- Quelle: 5. Hannover Herz Lungen Messe, 10.3.2017 in Hannover 